\title{
Agenda verde escolar: o uso de tecnologias na formação continuada de professores
}

\author{
Mônica Giacomassi de Menezes de Magalhães ${ }^{1}$ \\ monica@rc.unesp.br
}

\author{
Magda Adelaide Lombardo ${ }^{1}$ \\ magda@ceapla.unesp.ansp.br
}

\section{Resumo}

O objetivo deste trabalho foi o desenvolvimento da formação continuada de professores de do ensino fundamental I ( $1^{\circ}$ ao $5^{\circ}$ ano) na aplicação de material didático como parte da implantação da Agenda Verde Escolar. O TelEduc foi utilizado como tecnologia para auxiliar a integração de professores em um ambiente virtual. Professores de duas escolas municipais localizadas em um bairro de baixa renda da cidade de Rio Claro, São Paulo, Brasil, participaram do curso e adquiriram experiência no uso do ambiente virtual TelEduc, utilizando a internet como tecnologia de comunicação e informação. Após o curso, houve o acompanhamento dos professores nas escolas; a orientação de elaboração de projeto inserido no contexto da Agenda 21 Escolar e o acompanhamento na execução do mesmo. Além disso, houve a realização de evento envolvendo as escolas, prefeitura, universidade e comunidade local para apresentação dos resultados do projeto, os quais demonstraram a integração da comunidade local com a escola. A universidade participou ativamente no desenvolvimento do projeto e intensificou os laços do aluno com a escola e a comunidade no trato dos aspectos ambientais.

Palavras-chave: Agenda 21; educação continuada; tecnologia de comunicação e de informação.

${ }^{1}$ Centro de Análise e Planejamento Ambiental do Instituto de Geociências e Ciências Exatas da Universidade Estadual Paulista (Ceapla/IGCE/Unesp).

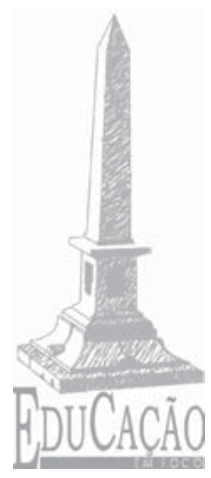




\section{Introdução}

As práticas de educação ambiental visam não somente a transmissão de conhecimento sobre o meio ambiente, mas também mudança de comportamento, determinação para as praxis e busca de soluções para os problemas. Nesse sentido, elas não se constituem numa nova disciplina, mas se apoia em várias disciplinas, numa abordagem interdisciplinar (LOMBARDO et al., 2007).

Segundo Lombardo (2000), os estudos sobre a qualidade ambiental vêm sendo enfatizados nas escolas públicas visto que a educação ambiental tem um caráter integrador e interdisciplinar. Ela exerce um papel renovador para a construção de uma melhoria da qualidade de vida da comunidade local.

Para se desenvolver um projeto de educação ambiental bem estruturado no ambiente escolar, utiliza-se como base conceitual o Tratado de Educação Ambiental para as Sociedades Sustentáveis e Responsabilidade Global, a Política Nacional de Educação Ambiental, a Carta da Terra e, em vários casos, a Agenda 21 Global (LOMBARDO et al., 2005).

A Agenda 21 Global é um documento elaborado em 1992 na Conferência das Nações Unidas, realizada no Rio de Janeiro (Brasil) com a participação de 179 países. Ela propõe diretrizes ambientais, sugerindo a prática de programas de ações com propostas de mudanças nos padrões de desenvolvimento para o século 21 (BRASIL, 1992).

Cada país pode desenvolver sua Agenda 21 de acordo com sua realidade, considerando-se suas condições ambientais, sociais e econômicas, já que o documento engloba diversas questões relacionadas ao desenvolvimento. A partir da Agenda 21 Nacional, cada estado e cada município também podem desenvolver seus próprios documentos, abordando assuntos ainda mais direcionados à sua realidade. Da mesma forma, dentro de um município, escola, empresa e outra entidade também podem ser desenvolvidos projetos ambientais com base nas propostas 
da Agenda 21. O importante é que esses documentos estejam relacionados com as propostas ambientais da Agenda 21 Global, que oferece parâmetros para a elaboração e implantação de projetos ambientais.

O programa Agenda 21 Escolar inicia-se com o conhecimento da escola e seu entorno. Forma-se um diagnóstico sobre o local, ressaltam-se suas qualidades e necessidades e propõem-se discussões de problemas levantados, tendo o objetivo de buscar soluções. Nesse programa existem diversos planos de ação como, por exemplo, coleta seletiva e reciclagem, reutilização de materiais, mudanças de hábitos de consumo para evitar os desperdícios, implantação de áreas verdes no entorno da escola, entre outros.

Segundo Olivato (2004), a Agenda 21 Escolar necessita do diálogo entre as diversas áreas, pois é um projeto interdisciplinar que visa envolver todo o corpo docente, com a contribuição integrada de vários campos do conhecimento e das suas respectivas metodologias por meio do diálogo. Outro aspecto importante para Agenda 21 é a construção de um plano de ação que visa resolver os problemas levantados pela comunidade.

De acordo com Lombardo et al. (2005), muitas experiências na implantação da Agenda 21 Escolar estão sendo trabalhadas no Brasil e em outros países por escolas apoiadas pela Secretarias da Educação e do Meio Ambiente.

A Agenda Verde Escolar é um projeto pedagógico baseado na Agenda 21 Escolar, focalizando a importância das áreas verdes e a qualidade ambiental, visando à implantação e ampliação das áreas verdes a partir da escola e de seu entorno.

A implantação da Agenda Verde Escolar tem como objetivo promover a mudança de atitude dos alunos com sua realidade, a fim de melhorar as condições socioambientais locais. Os alunos deverão receber informações do conteúdo do programa por meio de materiais didáticos. Os trabalhos práticos podem abranger uma análise do espaço do entorno de sua escola, conscientizando-os da real importância das áreas verdes na

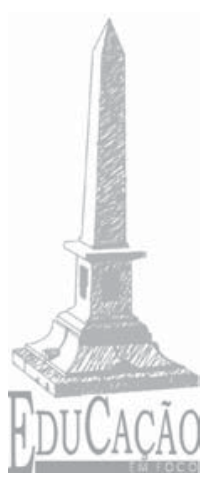

151 
comunidade local.

Nesse contexto, este trabalho compreendeu a formação continuada de professores através de atividades presenciais em sala de aula e a distância. Para isso, foi pesquisado um ambiente virtual, realizando a interação com os professores para a disponibilização e distribuição de material do curso.

Nesse ambiente os professores se comunicaram, bem como trocaram experiências, formando uma comunidade virtual de aprendizagem. Trabalhos desenvolvidos em salas de aula pelos professores também foram disponibilizados no ambiente virtual como exemplos práticos.

Trabalhos de campo com os professores foram realizados para mostrar os problemas ambientais, exercitando atividades que foram feitas posteriormente com seus alunos. Nessas atividades os professores vivenciaram na prática os problemas ambientais que mais afetam sua cidade, seu bairro ou o entorno de sua escola. As atividades foram baseadas na Agenda 21 Escolar, fornecendo subsídios práticos para sua aplicação. O plano de ação que envolve a aplicação do programa Agenda 21 Escolar foi desenvolvido com os professores a partir do conteúdo do material didático e dos trabalhos de campo.

\section{Desenvolvimento e aplicação}

Em 2008 o Centro de Análise e Planejamento Ambiental (Ceapla) do Instituto de Geociências e Ciências Exatas (IGCE) da Universidade Estadual Paulista (Unesp) desenvolveu o projeto sobre a implantação da Agenda 21 Escolar com ênfase no tema "Áreas Verdes". O projeto era destinado a professores do ensino fundamental de duas escolas públicas de um bairro carente do município de Rio Claro, estado de São Paulo, Brasil. O programa recebeu o nome de Agenda Verde Escolar e teve como base os documentos relativos à Agenda 21 Global.

Para implantação do programa, houve o conhecimento das es- 
colas e de seu entorno, destacando suas necessidades, através de visita da equipe do projeto nas escolas e no bairro. Após o conhecimento da comunidade local, foi desenvolvido o conjunto de material para alunos e professores do ensino fundamental, por meio de diferentes abordagens.

O material destinado aos alunos é composto por um conjunto de cadernos que os acompanharão ao longo dos primeiros anos do ensino fundamental. O material de apoio para os professores foi elaborado para embasar o planejamento das aulas e atividades, contendo conceitos sobre as diversas áreas do meio ambiente, descrição de problemas ambientais locais/regionais e sugestões de atividades.

Os temas trabalhados no material foram: $1^{\circ}$ ano - $\mathrm{O}$ verde da minha casa; $2^{\circ}$ ano - $\mathrm{O}$ verde da minha rua; $3^{\circ}$ ano - $\mathrm{O}$ verde do meu bairro; $4^{\circ}$ ano $-\mathrm{O}$ verde da minha cidade. As atividades foram baseadas na Agenda 21 Escolar, fornecendo subsídios para a prática do projeto Agenda Verde.

A partir do desenvolvimento do material de apoio, realizou-se o curso de formação continuada intitulado "Agenda 21: desenvolvimento da Agenda Verde Escolar" pelo Ceapla/IGCE/Unesp. O objetivo era formar professores (MAGALHÃES, 2004) para a aplicação da Agenda Verde Escolar com a utilização de um ambiente virtual de aprendizagem - TelEduc ${ }^{2}$. Nesse ambiente foi disponibilizado todo o material desenvolvido (FIG. 1), material para leitura, fotos dos trabalhos de campo com professores e alunos, discussões on-line, trabalhos dos alunos realizados em sala de aula e os relatos dos professores.

O TelEduc é um ambiente virtual para a criação, participação e administração de cursos pela internet. Foi desenvolvido com o objetivo de formar professores para a informática educativa, baseado na metodologia de formação contextualizada, desenvolvida por pesquisadores do Núcleo de Informática Aplicada à Educação $(\mathrm{Nied})^{3}$ da Unicamp.

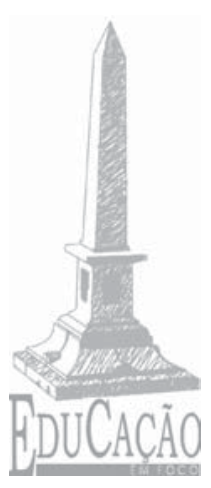

${ }^{2}$ http:/ / www.teleduc.org.br

${ }^{3}$ http:/ / www.nied.unicamp.br 


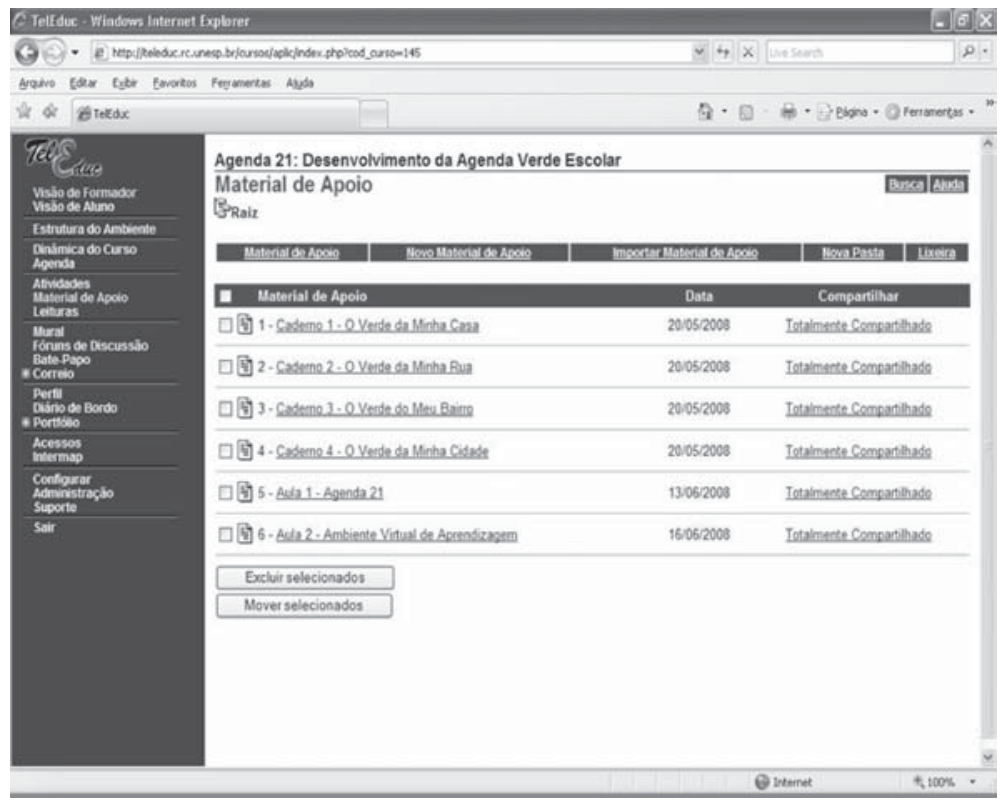

FIGURA 1 - Material de apoio do curso disponibilizado no ambiente TelEduc.

Os tópicos que envolvem a implantação do programa Agenda 21 Escolar, com ênfase no tema Áreas Verdes, foram trabalhados com os professores participantes do curso para que aplicassem as atividades do material em sala de aula. Isso com o objetivo de abranger toda a escola, propondo modelos de implantação da Agenda 21 a partir do conteúdo do material, do curso e dos trabalhos de campo.

Dando segmento ao curso de formação continuada, o programa envolveu o acompanhamento dos professores por meio de reuniões mensais, visitas às escolas, implantação de práticas ambientais com as crianças nas escolas e realização de evento para a divulgação dos resultados, envolvendo professores, dirigentes das escolas, prefeitura, universidade e comunidade do bairro. 


\section{Discussão dos resultados}

Destaca-se que o uso do TelEduc como um ambiente virtual de aprendizagem possibilitou a comunicação colaborativa em questões ambientais e favoreceu a troca de informações e de experiências entre os professores. Ele permitiu a formação de comunidades virtuais que se tornaram um banco de dados com conteúdo diversificado sobre Áreas Verdes, com textos sobre a Agenda 21 Escolar e imagens das áreas verdes da cidade, o que estimula as reflexões e participações no fórum de discussões.

Os participantes do curso tiveram diversas oportunidades, dando destaque a: conversas on-line com profissionais localizados em outras cidades sem precisar se distanciar da cidade onde trabalham, troca de experiências e informações, contato com novas tecnologias de comunicação e informação, participação em trabalhos de campo com imagens disponibilizadas no ambiente virtual, relatos de pares possibilitando reflexões e discussões on-line.

Os relatos sobre as atividades realizadas no decorrer do curso foram inseridos no ambiente virtual (FIG. 2). Assim, constituíram um material rico para análise das atividades práticas junto aos alunos, possibilitando a comunicação colaborativa. Verificou-se que o Ensino a Distância (EaD) representa uma ferramenta importante na formação continuada de professores, pois cada um se organiza segundo as suas possibilidades.

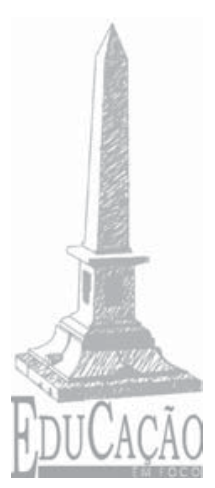

155 


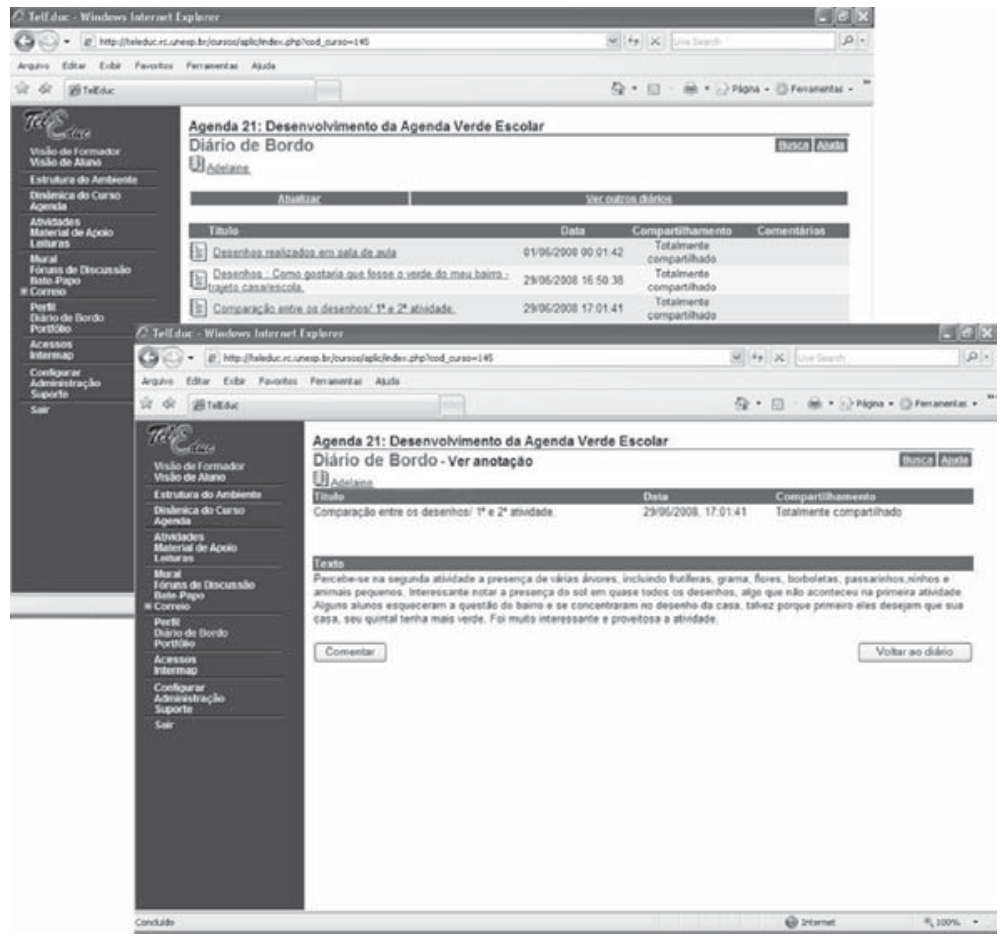

FIGURA 2 - Anotações inseridas no "diário de bordo" dos participantes do curso.

Todos os professores das escolas municipais envolvidas no projeto tiveram a oportunidade de levar seus alunos à Unesp, onde diversas atividades foram desenvolvidas com a coordenação da equipe do Ceapla e o apoio de alunos e funcionários da universidade, os quais colaboraram nessa etapa do projeto.

A questão ambiental foi abordada nas atividades de campo relacionadas ao tema Áreas Verdes. Isso possibilitou a oportunidade de os alunos conhecerem a universidade e parte das pesquisas e atividades desenvolvidas, uma vez que os participantes do projeto não conheciam a Unesp. Com essa atividade, além de trabalhar a questão ambiental com os alunos, buscou-se também despertar o 
interesse pelas atividades acadêmicas.

A partir das discussões realizadas e conhecimentos adquiridos no curso ministrado pela equipe do Ceapla, os professores aplicaram o material em sala de aula. De modo geral, os alunos demonstraram elevado interesse pelo material de apoio, pois ele integrou conceitos sobre áreas verdes e meio ambiente de uma forma simples, permitindo a compreensão rápida dos temas abordados. Alguns professores relataram que a grande quantidade de ilustrações e atividades do material desenvolvido contribuiu para despertar o interesse dos alunos. A aproximação dos conteúdos abordados com o cotidiano ajudou a despertar o interesse e facilitou a compreensão do tema.

Durante as reuniões de acompanhamento nas escolas, foram elaborados projetos para a implantação da Agenda 21 Escolar por meio da aplicação da Agenda Verde nas duas escolas participantes. Esses projetos consistiram no plantio de mudas na área interna das escolas - em frente às janelas das salas de aulas - para que pudessem fazer sombra e mudas nas calçadas em frente às escolas.

Após o plantio, os próprios alunos lembraram a professora de regar as árvores e fiscalizaram os seus colegas para a conservação das plantas. Portanto, os alunos tornaram-se os agentes estimuladores do processo de conscientização da escola.

Essas etapas desenvolvidas foram fundamentais para o sucesso do projeto. Entretanto, por ter sido realizado em 2008, sendo considerado curto o prazo de dois anos (2008/2010), as conclusões são ainda parciais. É necessário dar continuidade à implantação da Agenda Verde Escolar para que a integração entre a universidade e a comunidade local seja dinâmica, acompanhando as necessidades do bairro envolvido.

As experiências de outros projetos relacionados à Agenda 21 Escolar demonstram que os projetos tendem a durar por mais de um ano. Segundo Olivato (2004), os projetos, no geral, são de longa duração e tem como base a interdisciplinaridade.

No Brasil, o meio ambiente é tratado, de modo geral, de forma transversal conforme a determinação dos Parâmetros Curriculares

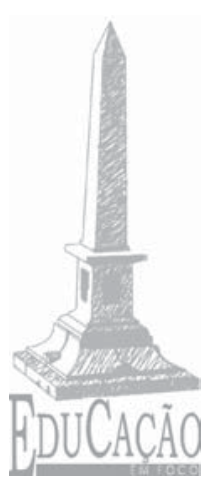


Nacionais e de forma multi, inter e transdisciplinar segundo a Política Nacional de Educação Ambiental. Dessa maneira, devido à complexidade da análise envolvendo várias disciplinas e alguns professores, a implantação da Agenda 21 Escolar requer um plano de ação que considere três fases temporais: curto, médio e longo prazo.

Quanto à amplitude e composição das experiências analisadas em outros projetos, destaca-se que os de longo prazo colaboram para diminuir a fragmentação do conhecimento, visando o diálogo constante entre os professores e entre os professores e alunos, envolvendo a participação dos docentes de diversas áreas.

\section{Conclusão}

A implantação da Agenda Verde Escolar no município de Rio Claro, São Paulo, constituiu-se de atividades teóricas e práticas que envolvem alunos e professores no trato de problemas ambientais e que podem ser aplicadas nos municípios como parte do projeto Agenda 21 Escolar.

O programa foi desenvolvido tendo como base os problemas de cada escola e da comunidade e constituiu-se na integração e parceria entre todas as entidades envolvidas.

O uso do TelEduc como tecnologia educacional foi de fundamental importância para a formação de comunidades virtuais. Assim, houve o incentivo à cooperação nas discussões do conteúdo programático sobre áreas verdes, bem como a troca de informações e experiências entre os professores.

Essa experiência demonstrou que a integração da universidade com a comunidade, via escola pública, intensifica um diálogo constante na aplicação do conteúdo programático. Com base nas práticas desenvolvidas junto aos alunos, é possível transformar a paisagem local, visando à melhoria da qualidade de vida.

É necessário dar continuidade ao projeto no município de Rio Claro de forma que a comunidade local construa um diálogo constante no trato das questões ambientais, contribuindo com as políti158 cas locais. 


\section{Referências}

BRASIL. Ministério do Meio Ambiente. Secretaria do Estado do Meio Ambiente. Agenda 21. Brasília, 1992. Disponível em: <http:/ /www.mma.gov.br/port/se/agen21>. Acesso em: 02 mar. 2008

LOMBARDO, M. A. Educação ambiental como subsídio à escola do futuro. In: FREITAS, M. I. C.; LOMBARDO, M. A. (Org.) Universidade e comunidade na gestão do meio ambiente. Rio Claro: AGETEO, Unesp, 2000. p. 27-62.

LOMBARDO, M. A.; VOLPE, L. L.; OLIVATO, D. Agenda verde escolar e educação ambiental. In: LOMBARDO, M. A (Org). Áreas verdes. Rio Claro: Unesp, 2005. p. 146-163.

LOMBARDO, M. A. et al. Tecnologia e ensino: aplicação da multimídia no estudo do meio ambiente e ciências atmosféricas. Série: Sociedade e natureza em ação, n.1, Rio Claro: IGCE/ UNESP, 2007. 52p.

MAGALHÃES, M. G. M. Metodologia para integração de novas tecnologias na formação de professores. 2004. 148 f. Tese (Doutorado em Ciências) - Instituto de Física, Universidade de São Paulo, São Carlos, 2004.

OLIVATO, D. Agenda 21 escolar: um projeto de educação ambiental para a sustentabilidade? Dissertação (Mestrado em Geografia) - Faculdade de Filosofia e Letras e Ciências Humanas, Universidade de São Paulo, São Paulo, 2004.

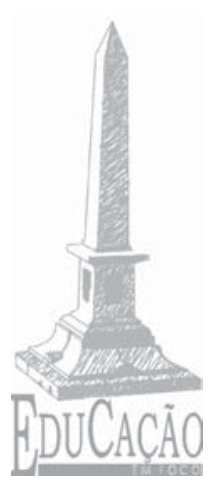

159 


\title{
Green school agenda: the use of technology in continuous teacher's training
}

\begin{abstract}
The objective of this work was the development of continuing teacher education of the Primary School in the application of didactic material, as part of the implementation of "Agenda Verde" for education. TelEduc was used as technology to facilitate the teachers' integration in a virtual environment. This work was applied in two municipal schools located in a poor neighborhood of the city of Rio Claro, state of São Paulo, Brazil, where the teachers participated of the course and they acquired experience in the use of the virtual environment TelEduc using the Internet as communication and information technology. After the course, the teachers were accompanied in the schools. They had orientation in the elaboration of the project inserted in the context of the "Agenda 21" for education and in the accompaniment in his execution. It was realized an event for the presentation of the results of the project that involved the schools, the city hall, the university and the local community. The results of the project demonstrated the integration of the local community with the school. The university has actively participated in the project development and increased integration of students with the school and the community in the treatment of the environmental aspects.
\end{abstract}

Keywords: Agenda 21, Continuing Teacher Education, Communication and Information Technology. 